\title{
Community-Based Study of Abortion Complications and Care Sought by Rural Tribal Women of an Extremely Low Resource Setting
}

\author{
Shakuntala CHHABRA ${ }^{1,2,3}$, Akanksha SUMAN ${ }^{1}$ \\ Amravati, India
}

ABSTRACT

OBJECTIVE: Knowing about complications, care sought by women is essential for understanding the risks, services, programs, and policies for abortion care. This study aimed to know the magnitude of abortion complications and to define the care sought by rural tribal women.

STUDY DESIGN: Rural community-based cross-sectional study was carried out in villages near Sewagram Wardha and Melghat, Amravati, Maharashtra, India.

RESULTS: Spontaneous abortions rate was $3.30 \%$ in villages around Sewagram and $0.32 \%$ in villages of Melghat. The reported complications rate for induced abortions was $1 \%$ in Sewagram villages and $0.1 \%$ in Melghat villages. In Sewagram villages, among $24(4.3 \%)$ women who had complications with spontaneous abortions, the reported complications were: vaginal bleeding in $33.3 \%$ (1.4\% of all spontaneous abortions), abdominal pain in $33.3 \%$, weakness in $29.16 \%$ (1.2\% all spontaneous abortions), backache in $16.6 \%$ ( $0.7 \%$ of spontaneous abortions), fever in $12.5 \%(0.5 \%$ of spontaneous abortions), excessive vaginal discharge in $8.33 \%$ ( $0.3 \%$ of spontaneous abortions), and other complications in $8.33 \%$ ( $0.36 \%$ of spontaneous abortions) women. Among 7 women (3.9\% of all 177$)$, who reported complications after induced abortions, $57.1 \%$ (2.2\% of all induced abortions) reported, vaginal bleeding and $28.5 \%$ (1.1\% of induced abortions) reported abdominal pain. In Melghat villages only 4 women reported complications with spontaneous abortions $(0.32 \%$ spontaneous abortions): two $(0.16 \%$ spontaneous abortions) reported abdominal pain, one ( $0.08 \%$ spontaneous abortions) reported vaginal bleeding, and one $(0.08 \%$ of spontaneous abortions) reported backache. In villages of Melghat 2 women $(3.7 \%)$ out of 27 induced abortions cases had complications: one had vaginal bleeding, discharge, pain, weakness, another only vaginal bleeding. In villages of Melghat 2 of the total 6 sought health facility care, however, no one reported to specialists despite complications. Nevertheless, there was neither abortion-related mortality nor near-miss morbidity or severe morbidity during the same duration.

CONCLUSION: Research is needed about traditional therapies, reverse pharmacology, socio-behavioral issues in addition to creating awareness in women about abortion complications, long-term squeal, and the necessity of care-seeking.

Keywords: Abortions, Community-based, Complications, Rural tribal women

Gynecol Obstet Reprod Med 2021;27(3):195-201

\footnotetext{
${ }^{1}$ Dr. Sushila Nayar Hospital, Utavali, Melghat, Amravati, India

2 Akanksha Shishugruha Kasturba Health Society Sevagram, India

${ }^{3}$ Mahatma Gandhi Institute of Medical Sciences, Sevagram, Wardha, Maharashtra, India

Address of Correspondence: Shakuntala Chhabra

Mahatma Gandhi Institute of Medical

Sciences, Sevagram, Wardha,

Maharashtra, India

chhabra_s@rediffmail.com,

schhabra@mgims.ac.in

Submitted for Publication: 12.08.2020 Revised for Publication: 15.10.2020

Accepted for Publication: 12.03.2021 Online Published: 14.04.2021

ORCID IDs of the authors: SC:0000-0003-3441-8571,

AS: 0000-0002-4551-9960
}

\begin{tabular}{c|c}
\hline Quick Response Code: & Access this article online \\
\cline { 2 - 2 } & Website: www.gorm.com.tr \\
& e- mail: info@gorm.com.tr \\
\hline & DOI:10.21613/GORM.2021.1139 \\
\hline
\end{tabular}

\section{Introduction}

Abortion, whether spontaneous or induced is the most common adverse outcome of pregnancy. Abortion complications continue to expose public health challenges globally, even more in developing countries. In many countries, induced abortions are still performed as unauthorized because of restricting abortion laws. Therefore, unsafe induced abortions continue to occur and result in maternal mortality globally (1). In regions where abortion is permitted, the utility of health facilities varies because of various reasons, which include lack of awareness and/or resources, secrecy, and beliefs in many

How to cite this article: Chhabra S. and Suman A. Community-Based Study of Abortion Complications and Care Sought by Rural Tribal Women of an Extremely Low Resource Setting. Gynecol Obstet Reprod Med. 2021;27(3): 195-201 
countries. Some complications like bleeding are inherent with abortion, both in spontaneous abortions (SA) or induced abortions (IA). Complications can occur in any case, even at safe health facilities. Therefore, abortions affect women's health globally. Singh reported that millions of women in the world suffered due to non-availability or non-use of appropriate treatment for abortion complications (2). Deaths resulting from abortions are preventable, yet they continue to occur because unsafe practices continue to go. After all, abortion is a personal and private aspect of a woman's life (3). The country's laws, policies, and programs affect the availability, utility of abortion services, and effects. Not much is known about the status of all such aspects of rural tribal women who either do not have services for abortion complications or do not have access or do not use available services.

This study aimed to collect community-based information about complications of SA and IA and care sought by rural tribal women living with extreme poverty in villages of two districts of Maharashtra, India.

\section{Material and Method}

After approval of the institutional ethics committee (28/09/2013, No. MGIMS/IFC/OBGY/42/2013), and in accordance with the Declaration of Helsinki, a communitybased cross-sectional study was carried out in villages of two districts of Maharashtra of India. Overall 65 villages in Dharni Block of Melghat in Amravati District and 53 villages near Sewagram of Wardha District were included, making a total of 118 villages, with a population of around one lac ten thousand. In these villages, maternal child services were started after creating a 24 hours and 7 days' health facility in one of in this remote hilly region where health problems were many, as a concept of social accountability of medical institute. In villages around Sevagram, maternal child services were started earlier. However, there was no information about abortions. Study subjects, women of 15-44 years from every fourth house, were interviewed by the research assistants. Those who had complications with SA or IA were defined as the study subjects. Informed consent for recording information on a hard tool was taken before administering the predesigned and pretested questionnaire in the local language by one-to-one, face-to-face interviews. Responses were recorded then and there on the questionnaire. No one was given a questionnaire to fill no time limit was kept. Focus group discussions (FGDs) were also conducted in villages with no age or abortion criteria. All those women of villages who were willing to participate in FGDs joined 8-10 in a group in any village.

\section{Results}

Of the 549 women who had SA abortions in villages around Sewagram in the Wardha district, 24 (4.3\%) said they experienced complications. For SA, the distribution of gesta- tional age at the time of complication was as follows: Four $(16.6 \%)$ at $6-9$ weeks, $10(41.6 \%)$ at $10-13$ weeks, $5(21 \%)$ 14-17 weeks, and 5 (21\%) 18-20 weeks. There was no specific definition of any complication. The question was asking about something which was thought to be abnormal with abortion, bleeding or pain was more than what was supposed to be normal. Of the 24 women who had complications, $33.3 \%$ (1.4\% of all SA) reported vaginal bleeding, $33.3 \%$ (1.4\% of SA) abdominal pain, $8.33 \%$ ( $0.3 \%$ of SA) vaginal discharge, $12.5 \%$ $0.5 \%$ of SA) fever, $29.16 \%$ (1.2\% of SA) weakness, $16.6 \%$ $(0.7 \%$ of SA) backache and $8.33 \%(0.36 \%$ of SA) other complications. Of the 24 women, 16 (66.7\%) sought services from Private hospitals, 3 (12.5\%) from Medical colleges, and 2 (8\%) from Sub-centres. Overall twenty-one (87.5\%) women were managed at health facilities. Three (12.5\%) women remained at home and family members gave home remedies (Table I). Of the total 177 cases of IA in villages around Sewagram, 7 (3.9\%) said they had complications with IA, three $(42.82 \%$ of 7$)$ had IA of 6-9 weeks' pregnancy, 2 (28.57\%) of $10-13$ weeks, one (14.28\%) of 14-17 weeks and one $(14.28 \%)$ of 18 - 20 weeks. All 7 women received medical therapy. Six of 7 women with complications sought care from private hospitals $(85.75 \%)$ and one from a public health facility (Table II). In the Melghat region, of 1217 women who had SA, only $4(0.32 \%)$ said they had complications, one each had an abortion of 6-9 weeks, 10-13 weeks, 14-17 weeks, and 18 -20 weeks' pregnancy. Of these 4 women, one $(0.08 \%$ of SA) had vaginal bleeding, 2 ( $0.16 \%$ of SA) abdominal pain, and one woman reported backache $(0.08 \%$ of SA). All 4 women had aborted at home and were managed by family members at home even for complications. No treatment was sought from any health facility. When asked about reasons for not using health facilities even for complications with abortions, one woman said there were no resources, one had transport problem and $2(50 \%)$ women had their own beliefs for not seeking care from any health facility. Three women (75\%) had home remedies and one sought the help of a local nurse midwife for additional medication at home (Table III). In villages of Melghat of the 27 women who had IA, 2 (7.4\%) said they had complications, one each had IA of 10-13 weeks and 18-20 weeks' pregnancy (Table IV). Not many reported any complications, more so in the Melghat region. During FGDs conducted in some villages it was revealed that women lacked awareness about possible complications of abortions. They had their own beliefs too. There were ignorance and misconceptions about abortion complications more so in the Melghat region where there was more poverty, illiteracy, access problems, lack of infrastructure, and scarce health facilities. However, there was no abortion-related maternal death, no near miss, not even severe illness in these villages over the years for which abortion complications information was sought (Table I, II, III, and IV). 
Table I: Spontaneous abortion-related complications in Sevagram region

\begin{tabular}{|c|c|c|c|c|c|c|c|c|}
\hline \multicolumn{9}{|c|}{ Total Cases- 24 In 53 Villages } \\
\hline Duration of Pregnancy & $\leq 6 w k s$ & $\geq 6-\leq 9 w k s$ & $\geq 10-\leq 13 \mathrm{wks}$ & $\geq 14-\leq 17 \mathrm{wks}$ & $\geq 18$ - $\leq 20 w k s$ & Total & & \\
\hline No. & - & 4 & $10^{*}$ & 5 & 5 & 24 & & \\
\hline$\%$ & - & 16.67 & 41.67 & 20.84 & 20.84 & 100 & & \\
\hline Place of Treatment & Quack & Sub-centre/PHC & District Hospital & Private Hospital & Medical College & Home & Total & \\
\hline No. & & 2 & 0 & $16^{*}$ & 3 & 2 & 24 & \\
\hline$\%$ & - & 8.34 & 0 & 66.67 & 12.5 & 12.5 & 100 & \\
\hline Person managing & Skilled & Untrained/Dai & Total & & & & & \\
\hline No. & $24^{*}$ & - & 24 & & & & & \\
\hline$\%$ & 100 & - & 100 & & & & & \\
\hline Management Mode & Medical & Evacuation on & Home-based & Total & & & & \\
\hline No. & $11^{*}$ & 10 & 3 & 24 & & & & \\
\hline$\%$ & 45 & 41.7 & 12,5 & 100 & & & & \\
\hline $\begin{array}{l}\text { Post-abortion } \\
\text { complications }\end{array}$ & $\begin{array}{l}\text { Vaginal } \\
\text { bleeding }\end{array}$ & $\begin{array}{l}\text { Vaginal } \\
\text { Discharge }\end{array}$ & $\begin{array}{l}\text { Abd. Pain } \\
\text { DistentionFever }\end{array}$ & $\begin{array}{l}\text { Weakness } \\
\text { Urinary }\end{array}$ & Backache Other & & & \\
\hline Number & $8^{*}$ & 2 & $8^{*}$ & 0 & 3 & 7 & 4 & 2 \\
\hline$\%$ & 33.34 & 8.33 & 33,34 & 0 & 12.5 & 29.16 & 16.66 & 8.33 \\
\hline \multirow[t]{2}{*}{ Post-abortion care } & Medical & Traditional & Others & None & Total & & & \\
\hline & $23^{*}$ & - & 1 & - & 24 & & & \\
\hline
\end{tabular}

Table II: Induced abortion-related complications in villages of Sewagram region

\begin{tabular}{|c|c|c|c|c|c|c|c|c|c|}
\hline \multicolumn{10}{|l|}{7 Cases In 53 Villages } \\
\hline Duration of Pregnancy & $\leq 6 w k s$ & $\geq 6-\leq 9 \mathrm{wks}$ & $\geq 10-\leq 13 w k s$ & $\geq 14-\leq 17 w k s$ & $\geq 18$ - $\leq 20 w k s$ & \multicolumn{4}{|l|}{ Total } \\
\hline Number & - & 3 & 2 & 1 & 1 & \multicolumn{4}{|l|}{7} \\
\hline$\%$ & - & 42.85 & 28.57 & 14.28 & 14.28 & \multicolumn{4}{|l|}{100} \\
\hline Place & Home & Sub-centre & $\mathrm{PHC}$ & $\begin{array}{l}\text { District } \\
\text { Hospital }\end{array}$ & $\begin{array}{l}\text { Private } \\
\text { Hospital }\end{array}$ & \multicolumn{2}{|c|}{ Medical College } & \multicolumn{2}{|l|}{ Total } \\
\hline Number & - & - & - & - & 7 & \multicolumn{2}{|l|}{-} & \multicolumn{2}{|l|}{7} \\
\hline$\%$ & - & - & - & - & 100 & \multicolumn{2}{|l|}{-} & \multicolumn{2}{|l|}{100} \\
\hline Care Provider & Self-induced & Dai & ANM/ASHA & Docto & Specialist & \multicolumn{4}{|l|}{ Total } \\
\hline Number & - & - & - & 5 & 2 & \multicolumn{4}{|l|}{7} \\
\hline$\%$ & - & - & - & 71.42 & 28.57 & \multicolumn{4}{|l|}{100} \\
\hline $\begin{array}{l}\text { Abortion } \\
\text { Provider }\end{array}$ & $\begin{array}{l}\text { Private } \\
\text { Hospital }\end{array}$ & $\begin{array}{l}\text { Public health } \\
\text { - }\end{array}$ & Home & Other & Total & & & & \\
\hline Number & 6 & - & - & 1 & 7 & & & & \\
\hline$\%$ & 85.75 & Nurse & - & 14.25 & 100 & & & & \\
\hline $\begin{array}{l}\text { Person } \\
\text { conducting }\end{array}$ & $\begin{array}{l}\text { Doctor / HP } \\
7\end{array}$ & - & $\begin{array}{l}\text { Untrained Dai } \\
\text { - }\end{array}$ & Total & & & & & \\
\hline Number & 100 & - & - & 7 & & & & & \\
\hline$\%$ & Medical & Surgical & Folk / Self & 100 & & & & & \\
\hline Method & 5 & 2 & - & Total & & & & & \\
\hline Number & 71.4 & 28.5 & - & 7 & & & & & \\
\hline$\%$ & Medical & Surgical & Traditional & 100 & & & & & \\
\hline Care Provider & 7 & - & - & None & Total & & & & \\
\hline Number & 100 & - & - & - & 7 & & & & \\
\hline$\%$ & Vaginal & Vaginal & Abd. Pain & - & 100 & & & & \\
\hline Complications & bleeding & Discharge & & Distention & Fever & Weakness & Urinary & Backache & Other \\
\hline Number & 4 & - & 2 & - & - & - & - & - & - \\
\hline$\%$ & 57.14 & - & 28.57 & - & - & - & - & - & - \\
\hline
\end{tabular}


Table III: Spontaneous abortion-related complications in villages of Dharni, Melghat region

\begin{tabular}{|c|c|c|c|c|c|c|c|c|c|}
\hline \multicolumn{10}{|l|}{ One In 65 Villages } \\
\hline Duration of Pregnancy & $\leq 6 \mathrm{wks}$ & $\geq 6-\leq 9 w k s$ & $\geq 10-\leq 13 w k s$ & $\geq 14-\leq 17$ wks & $\geq 18-\leq 20 w k s$ & Total & & & \\
\hline Number & - & 1 & 1 & 1 & 1 & 4 & & & \\
\hline$\%$ & - & 25 & 25 & 25 & 25 & 100 & & & \\
\hline Place of $1^{\text {st }}$ Treatment & Quack & Subcentre/P & District $\mathrm{H}$. & Private $\mathrm{H}$. & Medical College & & & & \\
\hline Number & - & $\mathrm{HC}$ & - & - & - & & & & \\
\hline$\%$ & - & - & - & - & - & & & & \\
\hline Care Provider & Family & - & ANM/ & Doctor & Specialist & & & & \\
\hline Number & 4 & Dai & ASHA & - & - & & & & \\
\hline$\%$ & 100 & - & - & - & - & & & & \\
\hline Person managing & Skilled & - & - & & & & & & \\
\hline Number & 1 & Untrained/ & Other & - & - & & & & \\
\hline$\%$ & 25 & Dai & 3 & - & - & & & & \\
\hline Management & Medical & - & 75 & - & & & & & \\
\hline Number & 1 & - & Home based & & - & & & & \\
\hline$\%$ & 25 & Evacuation & 3 & - & & & & & \\
\hline Post-abortion care & Medical & - & 75 & & & & & & \\
\hline Number & 1 & - & Others & None & & & & & \\
\hline$\%$ & 25 & Traditional & 3 & - & & & & & \\
\hline Post-abortion complication & Vagina I bleeding & - & 75 & & & & & & \\
\hline Number & 1 & - & 2 & Distention & - & - & - & 1 & - \\
\hline$\%$ & 25 & - & 50 & - & - & - & - & 25 & - \\
\hline
\end{tabular}

Table IV: Induced abortion-related complications in villages of Dharni Melghat region

\begin{tabular}{|c|c|c|c|c|c|c|c|c|c|}
\hline \multicolumn{10}{|l|}{ One (2) In 65 Villages } \\
\hline Duration of Pregnancy & $\leq 6 \mathrm{wks}$ & $\geq 6-\leq 9 w k s$ & $\geq 10-\leq 13 w k s$ & $\geq 14-\leq 17 w k s$ & $\geq 18$ - $\leq 20$ wks & Total & & & \\
\hline Number & - & - & 1 & - & 1 & 2 & & & \\
\hline$\%$ & - & - & 50 & - & 50 & 100 & & & \\
\hline Place of $1^{\text {st }}$ Treatment & Quack & Sub-centre/PHC & District $\mathrm{H}$. & Private $\mathrm{H}$. & Medical College & Home & Total & & \\
\hline Number & - & 1 & 1 & - & - & - & 2 & & \\
\hline$\%$ & - & 50 & 50 & - & - & - & 100 & & \\
\hline Care Provider & Family & Dai & ANM/ASHA & Doctor & Specialist & Total & & & \\
\hline Number & - & - & - & 2 & - & 2 & & & \\
\hline$\%$ & - & - & - & 100 & - & 100 & & & \\
\hline Person managing & Skilled & Untrained/Dai & Other & Total & & & & & \\
\hline Number & 2 & - & - & 2 & & & & & \\
\hline$\%$ & 100 & - & - & 100 & & & & & \\
\hline Management & Medical & Evacuation & Home based & Total & & & & & \\
\hline Number & 2 & - & - & 2 & & & & & \\
\hline$\%$ & 100 & - & - & 100 & & & & & \\
\hline Post-abortion care & Medical & Traditional & Others & None & Total & & & & \\
\hline Number & 2 & - & - & - & 2 & & & & \\
\hline$\%$ & 100 & - & - & - & 100 & & & & \\
\hline $\begin{array}{l}\text { Post-abortion } \\
\text { complication }\end{array}$ & $\begin{array}{l}\text { Vaginal } \\
\text { Bleeding }\end{array}$ & $\begin{array}{l}\text { Vaginal } \\
\text { Discharge }\end{array}$ & Abd. Pain & Distention & Fever & weakness & Urinary & Backache & Other \\
\hline Number & 1 & 1 & 1 & - & 1 & 1 & 1 & 1 & - \\
\hline$\%$ & 50 & 50 & 50 & - & 50 & 50 & 50 & 50 & - \\
\hline
\end{tabular}




\section{Discussion}

Early and late complications do occur with or after SA or IA, either because abortions are managed by untrained persons or at unsafe places or by unsafe modes or because of inherent problems like bleeding with abortion which can occur anytime, irrespective of the person performing or place of abortion. Even a woman with SA can have heavy bleeding, long-term squeal, and recurrence too. Complications also depended on the duration of pregnancy which got aborted. The concept of post/peri abortion care (PAC) has evolved in the recent past. It is a global approach towards reducing maternal mortality and morbidity due to complications of SA and IA with various medical and social interventions to ensure improvements in women's sexual and reproductive health (4). The essential elements of PAC include emergency treatment of incomplete abortion, bleeding, infection, fever, pain as well as contraceptive counseling with desired services and linkage to other emergency services. However, the mortality and morbidity risks associated with safe or unsafe IA not only depend on the availability and quality of abortion care but also on woman's beliefs, willingness, and ability to seek services. Ganatra et al reported that around 25 million unsafe abortions (45\% of all abortions) occurred between 2010 and 2014, every year worldwide (5). The majority of unsafe abortions (97\%), were in developing countries (Africa, Asia, and Latin America). WHO also reported that 19 of every 20 unsafe abortions took place in less developed regions of the world (6) and this was where $98 \%$ of abortion-related deaths occurred (7). So women's perceptions, beliefs, and health-seeking matter a lot.

An estimated 6.8 million abortions occurred every year in South Central Asia, at a rate of 17 unsafe abortions per 1000 women (8). Systematic analysis of 417 data sets from 115 countries estimated the prevalence of maternal deaths from abortive outcomes (ectopic pregnancy inclusive) as $8 \%$. Overall, sub-Saharan African countries had the highest contribution to maternal deaths due to abortive outcomes (9). Haddad et al also reported that worldwide 47000 women died due to complications of unsafe abortions, representing $13 \%$ of pregnancy-related deaths (10). A review of various studies by Johnston revealed that nearly $18 \%$ of all maternal deaths in India, were abortion-related (11). Present community-based study of the magnitude of SA or IA-related complications care sought by rural tribal women of two Districts of Maharashtra, India, was carried out to know the community-based burden of abortion complications. There were access problems, lack of resources, lack of awareness, scarce health services, and also quite a few things that were not obvious in Dharni Block of Melghat, a hilly forestry region with extreme poverty. However, overall 3.3\% of women reported complications with SA in villages around Sewagram and $0.3 \%$ women in villages of Dharni of Melghat, 10 times less in the Melghat region. In villages of the Sewagram region care providers were family members, medical officers, specialists, traditional birth attendants, and ASHAs in $62 \%, 25 \%, 12 \%, 2 \%$, and $1 \%$ respec- tively. Overall $12.5 \%$ of the 24 women who had complications were managed at home and $66.7 \%, 12.5 \%$, and $8.34 \%$ were managed at Private hospitals, Medical Colleges, and District hospitals respectively. Care seeking seemed to be related to awareness, resources, access to available facilities, and beliefs also. Family members were care providers for those who remained at home and the rest $22.5 \%$ were managed by medical officers and only $3.75 \%$ by specialists at health facilities. Abortion is usually kept secret and so private services are sought more often. In these villages' tribal women even with extreme poverty sought private services. Policymakers need to know about this aspect of abortion care. In a study, at least $9 \%$ of abortion-related hospital admissions had a near-miss event and around $1.5 \%$ ended in death (10). Hemorrhage was the most common complication reported. The pooled percentage of abortion-related hospital admissions with severe hemorrhage was $23 \%$, with around $9 \%$ were having near-miss morbidity due to hemorrhage. Results suggested that a substantial percentage of abortion-related hospital admissions had potentially life-threatening complications. The present study revealed that in the rural community, $1 \%$ of women reported complications with IA, in the form of heavy vaginal bleeding and pain in the abdomen in the Sewagram region, and $0.16 \%$ of women in the Melghat region not very high numbers. These eventful IA in villages around Sewagram were cases performed at private hospitals, either for spacing (29\%) or for health reasons $(71 \%)$ and were conducted by medical means in $71 \%$, and surgical procedures in $28 \%$. Whatever was easily available was used was obvious. However, there were no major problems reported. No one seemed to have complications to cause near misses or even severe illness. There was no abortion-related death in these villages during the whole duration. Furthermore, women with a pregnancy of 10-13 weeks had complications. It is a grey zone. At this gestation medical methods are not used and surgical procedures are likely to cause trauma. Also, it is known that second trimester IA carried a higher risk of complications but they continued in this region. However dangerous complications did not occur even in these women. With FGDs it was obvious that there was a lack of awareness about possible complications. In a study, it was found that in seven of ten countries, less than $10 \%$ of primary level facilities could provide basic PAC, and in eight of ten countries less than $40 \%$ of referral-level facilities could provide comprehensive PAC (12). In a study, $7.9 \%$ of women experienced complications (13). The case fatality rate was worst for abortion-related infections (19.1\%). In the present study, the most common post-abortion complications reported were excessive vaginal bleeding and lower abdominal pain but neither in many women nor was the bleeding heavy to severe illness or near-miss morbidity. Other less frequent complications were high-grade fever, foul-smelling discharge, backache, and weakness; probably infection-related but still did not lead to severe illness. A community-based study in Madhya Pradesh revealed that more than one out of two IA 
among rural women $(57 \%)$ and more than two of five IA among urban women (46\%) resulted in at least one complication (14). It was not found in the present study which was community-based in villages with extreme poverty. Whatever information was possible verbally was collected and analyzed. There were no records. Because of linkage with maternal services in these villages information about the severe illness, near-miss cases, maternal deaths due to any reason was available. Therefore, it was obvious that in this region there were not many problems in abortion cases.

Doorman et al reported that indigenous people and local communities (IPLCs) knowledge and practices rely on holistic and integrative conceptualizations of nature and value systems acknowledging interlinked human-nature relations (15). IPLCs hold a body of knowledge that has been accumulated through generations within their specific cultural and environmental context. Using knowledge systems as equal partners informing one another requires bridging them, rather than synthesizing them. Knowledge co-production as a dialogue and partnership can harness the practical wisdom and cultural values of IPLCs towards innovative solutions. A lot of research is needed about home practices, especially because there were no major complications. In the present analysis, not many complications were reported and no services were sought by many women even for complications. Primary Health Centre, Sub-centre did not provide PAC.

\section{Conclusion}

Awareness is needed about abortion complications. Also, a lot of research is needed about traditional medicine, reverse pharmacology, and socio-behavioral aspects too.

Acknowledgment: We are grateful to the Indian Council of Medical Research (ICMR), New Delhi for the financial support for doing the study. We thank the Director General ICMR, and also everyone in the division of Reproductive Biology and Maternal Health Child Health, ICMR New Delhi, especially Ex-Chief, Dr. Malbika Roy, Dr. R. S. Sharma, and Dr. Shalini Singh for all the help and support. We are also grateful to Dr. $R$. B. Shrivastav and others at ICMR headquarters. We thank the rural tribal women for the cooperation in conducting the study. I am grateful to my colleagues Dr. Suchi Jain, Dr. Naina Kumar, Dr. Ketki for all the help. Thanks also to all the research assistants office staff for the information collected and help in the analysis of the data and documentation.

Conflict of Interests: There were no conflicts of interest, financial, personal, political, intellectual, or religious.

Funding: Funding for the study was provided by the Indian Council of Medical Research, New Delhi, India.

Details of Ethics Approval: The study was carried out after approval of the ethics committee of the Institute, Dated 28/09/2013, No. MGIMS/IFC/OBGY/42/2013

Authors'contributions: SC: Chhabra conceived the presented idea, contributed to the design and implementation of the research, to the analysis of the results, and the writing of the manuscript. AS: Contributed to the final analysis and documentation of the results.

\section{References}

1. Fawcus SR. Maternal mortality and unsafe abortion. Best Pract Res Clin Obstet Gynaecol. 2008;22(3):533-48. Doi: 10.1016/j.bpobgyn.2007.10.006.

2. Singh S, Maddow-Zimet I. Facility-based treatment for medical complications resulting from unsafe pregnancy termination in the developing world, 2012: a review of evidence from 26 countries. BJOG. 2016;123(9):1489-98. Doi: 10.1111/1471-0528.13552.

3. Grimes DA, Benson J, Singh S, Romero M, Ganatra B, Okonofua FE, et al. Unsafe abortion: the preventable pandemic. Lancet. 2006;368(9550):1908-19. Doi: 10.1016/ S0140-6736(06)69481-6.

4. Evens E, Otieno-Masaba R, Eichleay M, McCarraher D, Hainsworth G, Lane C, et al. Post-abortion care services for youth and adult clients in Kenya: a comparison of services, client satisfaction and provider attitudes. J Biosoc Sci. 2014;46(1):1-15. Doi: 10.1017/S0021932013000230.

5. Ganatra B, Gerdts C, Rossier C, Johnson BR Jr, Tunçalp Ö, Assifi A, et al. Global, regional, and subregional classification of abortions by safety, 2010-14: estimates from a Bayesian hierarchical model. Lancet. 2017;390 (10110): 2372-81. Doi: 10.1016/S0140-6736(17)31794-4.

6. Unsafe Abortion. A major public health problem. Safe motherhood. 2000;28(1):4.

7. Sixth edition World Health Organization, Geneva 2011. Unsafe abortion: global and regional estimates of the incidence of unsafe abortion and associated mortality in 2008. Pages: 1-66. Available at: http://apps.who.int/iris/bitstream/10665/44529/1/9789241501118_eng.pdf

8. Shah I, Ahman E. Unsafe abortion in 2008: global and regional levels and trends. Reprod Health Matters. 2010; 18(36):90-101. Doi: 10.1016/S0968-8080(10)36 537-2.

9. Say L, Chou D, Gemmill A, Tunçalp Ö, Moller AB, Daniels J, et al. Global causes of maternal death: a WHO systematic analysis. Lancet Glob Health. 2014;2(6):e32333. Doi: 10.1016/S2214-109X (14)70227-X.

10. Haddad LB, Nour NM. Unsafe abortion: unnecessary maternal mortality. Rev Obstet Gynecol. 2009;2(2):122-6. PMID: 19609407.

11. Johnston HB. Abortion practice in India: a review of literature. Mumbai: Centre for Enquiry into Health and Allied Themes; 2004. Pages: 1-23.

12. Henshaw RJ, Henderson MW, Luebrecht DE, Gallagher MP, Ahigian EE, Bergman BA, inventors; Crown Equipment Corp, assignee. Control handle for a materials handling vehicle. United States patent application US 29/060,045. 1999 Feb 9. 
13. Maxwell KN, Cholst IN, Rosenwaks Z. The incidence of both serious and minor complications in young women undergoing oocyte donation. Fertil Steril. 2008;90 (6):2165-71. Doi: 10.1016/j.fertnstert.2007.10.065.

14. Duggal R, Ramachandran V. The abortion assessment project--India: key findings and recommendations.
Reprod Health Matters. 2004;12(24 Suppl):122-9. Doi: 10.1016/s0968-8080(04)24009-5.

15. Doorman L, Reyes-Garcia V, Martin- Lopez B, Berkes F. Learning from indigenous populations and local communities. One Earth. 2009;1(1):16-7. Doi: 10.1016/j.oneear. 2019.07.002. 